\title{
TRABALHO, MORADIA E CIDADE Zonas de indiferenciação?
}

\section{Cibele Saliba Rizek}

\section{Descrição das zonas de indiferenciação}

Esse artigo discute, com base em um conjunto de achados de cunho etnográfico, ${ }^{1}$ a formação de um campo de forças entre velhos e novos processos que articulam cidade e trabalho. Essas forças estruturantes permitem que se vislumbrem os novos tempos da produção financeirizada e mundializada em seus entrelaçamentos com o que se poderia indicar, ainda que de modo bastante livre, como elementos de uma "mundialização por baixo" - como a presença do chamado "custo chinês" e sua incidência sobre a produção e os fluxos de circulação de riqueza na cidade de São Paulo. Essas dimensões e achados estão ancorados em um conjunto de debates recentes sobre as questôes da cidade, das "classes populares" ou de seus territórios, em que novas relaçōes têm marcado o caráter nebuloso ou, ao menos, distante

Artigo recebido em 25/10/2010

Aprovado em 28/07/2011 dos referenciais clássicos pelos quais as cidades e seus territórios foram descritos e analisados até então.

É possível, assim, recorrer às noções de porosidade e liminaridade, ou de zonas cinzentas, ou mesmo de indeterminações que perpassam autores, temas, tentativas de compreensão. Neste artigo observo que a noção de indiferenciação aqui esboçada se refere a esse conjunto mais ou menos recente de transformaçōes, em que a experiência do trabalho para além do trabalho fabril - e da cidade - para além das referências dualizadas como centro e periferia, presença ou ausência do Estado, lugar de trabalho e lugar de moradia - se embaralharam. Interessa sobretudo destacar que essas novas experiências também marcam diferenças geracionais que, por assim dizer, apontam para mudanças dos tempos sociais. Nesse terreno de zonas cinzentas, algumas redefiniçōes parecem se desenhar. Uma delas é a que permite perceber que a experiência do trabalho e de sua precarização ou encolhimento formal, 
daquilo que Oliveira (2003) chamaria de "trabalho sem forma", ganha contornos na experiência da cidade $^{2}$ talvez pela inserção em territórios também eles, como diria Oliveira, "faltos de forma", genéricos, indiferenciados, mas crescentemente marcados por fluxos de produção e circulação de riqueza, ainda que esses fluxos estejam, eles também, em zonas nebulosas e cinzentas, zonas de indiferenciação. ${ }^{3}$

Aqui também talvez seja preciso observar que algo dessas zonas cinzentas, indiferenciadas, aparece na ideia de cidade genérica (Koolhaas, 2007), à qual se poderiam acrescentar apenas modulaçôes, ou mesmo nas dimensões que apontam para processos de fragmentação e dualização urbanas, leituras que sugerem o esgotamento da operação das velhas determinações que dão ao espaço funçōes claramente definidas: o espaço da produção, o espaço da reprodução - entre os quais os espaços da moradia que conformavam territórios e territorialidades passíveis de serem claramente identificadas, como bairros operários, por exemplo.

Em pesquisas recentes e livros sobre as questôes do trabalho e da cidade contemporânea, essas conformações são abordadas de modo diverso, como por exemplo o livro Viver em risco de Lucio Kowarick (2009); ou também alguns dos textos que compõem São Paulo, la ville d'en bas, organizado por Cabanes e Georges (2009), em que moradia e trabalho se entrelaçam quase necessariamente em fluxos de produção e circulação de mercadorias localizados em zonas indiferenciadas entre legalidades e ilegalismos; há ainda a ideia de dobra entre o legal e o ilegal, tal como aparece em artigos de Vera Telles. ${ }^{4}$ Esses trabalhos, não por acaso, resultam de processos etnográficos de pesquisa e de um conjunto denso e, às vezes, bastante intrincado de formas descritivas.

De qualquer maneira, como ler novos e velhos vínculos entre a cidade, seus territórios, suas formas de segregação e estratificação e as inserçōes produtivas? Entre cidades e esse conjunto de transformaçōes, torçōes e tensōes que parecem articular de outro modo antigas binaridades em muitos dos campos de investigação social? Como é possível flagrar os processos que combinam de modo inusitado velhas e novas relaçóes entre trabalho e moradia, entre dimensões sociais e produtivas e outras formas associativas, ou dimensōes provenientes do campo socioassistencial, apenas para citar alguns exemplos? $\mathrm{Na}$ pesquisa ora em andamento "Cidade, civilidade e seus avessos: tessituras e gestão dos territórios da precariedade", 5 as tessituras urbanas só puderam ser apreendidas por um conjunto de incursões a campo de cunho rigorosamente etnográfico: observaçōes, cadernos de campo, longas entrevistas, análise, interpretaçōes, tentativas de apreensão de trajetórias, terreno bastante distante dos grandes mapeamentos de dados ou da sistematização de informações de natureza quantitativa. Trata-se de um modo de apreensão e de descrição de transformações em curso que geram verdadeiros desafios para as visōes teóricas e conceituais mais clássicas.

Esses elementos levantam questóes que poderiam ser formuladas nos termos que se seguem. Que validade e legitimidade se podem atribuir, em tempos de tanta transformação, às teorias clássicas que analisam as forças estruturantes da vida social, localizando-as nas relações de trabalho e produção, nas relações sociais daí provenientes e de seus desenhos no espaço urbano cada vez mais diversificados e, aparentemente, mais fragmentados? Como pensar, desse ponto de vista, as relaçóes complexas entre territórios urbanos, pobreza e trabalho? Muitos dos processos identificados como contemporâneos - financeirização e transformação das relaçōes com o trabalho e de trabalho - parecem apontar para a erosão ou a dissolução dos vínculos de estruturação que desde a revolução industrial desenhavam arranjos e cadeias produtivas pela proximidade de mercados e pela polarização e concentração da força de trabalho. Ganhavam forma e ritmo na cidade industrial os espaços e os tempos de trabalho e sua articulação com os modos de vida, relações sociais inter e entre classes, conformaçôes das classes no território urbano e, nesse sentido, fisiognomias urbanas resultantes tanto desses processos como da distribuição de equipamentos e investimentos públicos e privados. A expressão cidade fordista é um exemplo dessas associaçôes que, se não podiam ser consideradas propriamente conceitos, ao menos podiam ser vistas como categorias descritivas que tinham o poder de sintetizar uma situação socioespacial de trabalho e de vida.

Diante do esgotamento dessas conformações, seria possível identificar configuraçôes urbanas posteriores com categorias de mesmo peso descritivo e 
analítico? O esvaziamento do fordismo é frequentemente identificado com a explosão da cidade em um conjunto fragmentário de territórios que, justapostos, funcionariam mais como mosaico do que como um todo estruturado. Os "pedaços" financeirizados e mundializados das cidades contemporâneas podem ainda ser vistos sob o signo de um conjunto de determinaçōes comuns, ou estas também se fragmentaram e perderam seu poder de estruturação?

É verdade que a partir do mapeamento dos novos ordenamentos produtivos ${ }^{6}$ a questão das cidades, crescentemente vistas como "cidades globais" e, assim, como territórios fragmentados, descentrados, modulados - cidades dominadas por atividades vinculadas ao terciário avançado e mundializado -, comparece como uma espécie de testemunho do processo de perda de centralidade do trabalho assalariado ou ainda de perda da capacidade de estruturação e determinação dos processos produtivos sobre os territórios urbanos.

Esse artigo pretende mostrar que as mesmas forças estruturantes estão presentes, ainda que moduladas conforme os novos tempos da produção, a partir de uma combinação entre financeirização mundializada e um conjunto de outros processos que podem ser identificados com o que alguns autores chamaram de "mundialização por baixo" (Tarrius, 2002). ${ }^{7}$ A expressão "custo chinês" é um exemplo dos desdobramentos de tal processo, com consequências no âmbito da produção e dos modos de circulação de riqueza. Se a expressão pode representar no contexto europeu porosidade, trânsito entre fronteiras, migraçōes internacionais de novo tipo, formas comerciais que atravessam os polos formais e informais de circulação e consumo, é possível observar, por outro lado, modulaçôes desses mesmos processos, que se articulam com migraçóes de novo tipo como, por exemplo, a presença boliviana no Brasil e, particularmente, em São Paulo. Parte desse processo de "mundialização por baixo" acontece por via de uma transformação silenciosa, nem sempre visível, de espaços urbanos, cuja natureza vem se reformulando sem que se possa perceber imediatamente o sentido e os mecanismos dessas transformaçōes. Talvez aqui resida a especificidade deste texto, qual seja, analisar justamente tal invisibilidade que atravessa tanto os territórios como as relações de trabalho. Essa refle- xão aponta para uma elipse das formas clássicas que relacionavam o "mundo da moradia" e o "mundo do trabalho". Redescobrindo o que está subjacente, percebem-se relações e formas de trabalho embaralhadas, mas nem por isso menos estruturantes das experiências vividas circuitos e territórios urbanos. hoje nas cidades. Desse ponto de vista é possível identificar mais uma fronteira porosa, ou mais uma dobra - já que é pouco provável que existam dois lados separados por linhas reais e/ou imaginárias -, cujas ambiguidades parecem ser elementos que constituem e definem vínculos e modos de inserção, sem os quais as próprias situações de trabalho - a indiferenciação entre trabalho associado e assalariado, postos de trabalho provenientes de programas supostamente virtuosos de geração de emprego e renda e a assimilação do trabalho precarizado - não seriam possíveis.

\section{Circuitos de produção e circulação de riqueza}

Nas fronteiras leste da cidade de São Paulo é possível afirmar, ainda que de modo incipiente, que antigos "bairros dormitórios", constituídos por conglomerados de apartamentos e financiados por programas de habitação social, assim como loteamentos populares frequentemente irregulares e autoempreendidos, se transmutaram em novos territórios produtivos (Lago, 2010), embora não se possa observar ali nenhuma unidade industrial em funcionamento. $\mathrm{O}$ mesmo ocorre em nichos de produção, moradia e comercialização do centro da cidade, onde pululam oficinas de costura e transitam trabalhadores que em geral moram e trabalham em situações limite, dificilmente passíveis de serem descritas como trabalho em domicílio. ${ }^{8}$ Evidentemente, esses territórios produtivos têm, à primeira vista, formato inusitado, constituído por novas relaçōes de trabalho, que se desenvolvem como arremedos das velhas formas de trabalho em domicílio ${ }^{9}$ ou que se assemelham a manufaturas rústicas, com baixo nível de mecanização, isto é, caracterizadas pelo uso intensivo de trabalho com margens mínimas de investimento, mas legitimadas por programas sociais e/ou por programas de geração de emprego e renda. 
Assim, é possível caracterizar Cidade Tiradentes, um bairro construído pelo governo de São Paulo na década de 1980, a 35 quilômetros do centro da cidade, como um nó em um circuito de produção de confecções, dentro e fora dos apartamentos, em cooperativas e em domicílios, cujo produto final segue para grandes lojas de consumo popular ou de luxo, para a "feirinha da madrugada", ou, ainda, empreendimentos financiados e apoiados pelo Ministério dos Esportes. Bairro constituído por conjuntos habitacionais populares, verticalizados ou unifamiliares - à primeira vista um grande bairro dormitório -, considerado "caixotes da exclusão", Cidade Tiradentes configura um aglomerado de oficinas de costura individualizadas, terceirizadas ou subcontratadas em cadeia por outras unidades maiores ou agenciadas por "gatos" que subcontratam costureiras com ou sem máquinas para tarefas finais da cadeia de confecções. Ou seja, há ali um conjunto de novas e velhas possibilidades de trabalho que se desenvolve tanto no interior das moradias transformadas em oficinas de costura, como em cooperativas de maior porte. Nessas relações, ganha corpo a possibilidade de exploração e absorção das parcelas mais vulneráveis de trabalhadores mulheres negras, idosas, mulheres chefes de família em situações extremamente precárias, cujo trabalho se combina com atividades cooperativas ou pseudocooperativas, de presidiários, de "autônomos", tanto no âmbito da produção como no dos circuitos cujo espectro é bastante amplo: a "modinha" do Brás, as feiras e shoppings populares do centro, as grandes lojas âncoras, fábricas de maior porte, além da confecção de camisetas, bolsas, bonés e bandeiras para atividades esportivas oficiais, inclusive as bandeiras brasileiras que os atletas exibiram nas últimas Olimpíadas. ${ }^{10}$

As ambiguidades, as articulações e o modo pelo qual essa população enfrenta sua condição de trabalho e de vida refletem ainda elementos surpreendentes: a constituição de um mix, também ele da ordem das indiferenciações que dão título a este texto, entre trabalho social, associado (ou autodefinido como tal) e assalariado, nas suas formas menos reguladas e mais precárias. ${ }^{11} \mathrm{E}$ essa situação constatada na Cidade Tiradentes se reproduz pelas periferias mais pobres da cidade.
Cooperativas e agrupamentos são resultantes de programas de geração de emprego e renda, ou ainda "empreendimentos de economia solidária" somados à iniciativa e ao financiamento de fundações empresariais, a que se agregam programas estatais, financiados direta ou indiretamente pela inversão de fundos públicos. Essa nova articulação, mesclada e porosa, dissimula uma das características mais notáveis desse do processo produtivo. ${ }^{12}$ Trata-se de certa informalidade - muito diversa da informalidade clássica - que aparece em graus variados e bastante embaralhados: desde formas brutais de exploração sem qualquer regulação caso dos trabalhadores cooperados e em domicílio da Cidade Tiradentes - até relações de cunho empresarial constituídas a partir de um "trabalho autônomo" mais formalizado - caso da Central de Triagem de resíduos sólidos da Vila Curuçá -, com obrigatoriedade do pagamento do INSS e algum grau de seguridade. Pode-se dizer que, neste caso, o trabalho deixou de ser tão informal, ainda que com limites muito fluidos entre estar dentro e fora da "cooperativa", entre poder trabalhar e sobreviver ou ser "demitido" sem quaisquer compensações.

Chegamos, pois, à segunda situação a ser considerada no âmbito desses novos modos de inserção: o circuito de triagem e reciclagem de resíduos sólidos. ${ }^{13} \mathrm{O}$ processo de reciclagem acontece a partir de um circuito que supõe trabalho de catação, centralização intermediária do produto em núcleos com algum processamento (por exemplo de plásticos) e organização de cooperativas de triagem. Ao mesmo tempo, ocorre a face mais "empresarial" do processo, as centrais de triagem. Aqui (assim como no caso já mencionado das cooperativas de costura) a articulação de diferentes atores - Ongs, empresas, empreendimentos solidários, elementos provenientes de programas sociais e políticas públicas dificulta o entendimento do caráter e da forma do processo produtivo em curso. De que se trata, afinal? Qual o estatuto do trabalho e das relações de trabalho que, nesse caso, só podem acontecer "em rede" ? ${ }^{14}$ Onde e como se articulam tais redes? Elas podem ser entendidas como eixos estruturantes do território ou, ao contrário, levam a uma desterritorialização? Quais são os elementos que as definem como circuitos produtivos ou de valorização e cir- 
culação de riqueza? Como e quais atores se articulam no seu interior?

Os encontros com trabalhadores da reciclagem na fronteira leste da cidade de São Paulo mostraram que, a partir do Fórum do Lixo e das iniciativas da prefeitura de São Paulo durante a gestão Marta Suplicy (2001-2004), se abriu a possibilidade de novas inserçōes e relações de trabalho, para além dos conhecimentos pessoais, da pertinência e da moradia em um mesmo bairro. Nesse sentido, todo um conjunto de dimensões configurou-se, a começar pelo vínculo com o trabalho de catação, cujo reconhecimento é resultado da bandeira de luta do movimento de catadores e do movimento da população em situação de rua (Barros, 2004).

$\mathrm{O}$ circuito inclui desde o catador até as grandes empresas - algumas com destacado papel na composição dos mercados setoriais -, passando por redes de supermercados e shoppings, onde o material é coletado. Uma parcela desse material tem como destino grandes unidades de produção, que compram e reutilizam o material proveniente da reciclagem, como empresas de papel, plástico, embalagem, empresas metal-mecânicas, entre outras, passando por núcleos que se configuram como pequenas empresas familiares, cujo estatuto empresarial é também de difícil reconhecimento, dada a precariedade das instalaçóes e dos rendimentos auferidos. Todos esses nódulos "em rede" parecem se revestir de dimensões mais ou menos ideológicas de "sustentabilidade", "proteção e preservação ambiental". São "ambientalizados", 15 e funcionam como núcleos intermediários de triagem e tratamento dos dejetos até a chegada do produto nas grandes centrais, entre as quais a da Vila Curuçá, também organizada como cooperativa, mas cada vez mais revestida de uma lógica empresarial; distante, portanto, do núcleo familiar ou da autogestão de cooperativas, concebidas como alternativas de geração de emprego e renda. ${ }^{16}$ De qualquer maneira, esse gradiente de pontos de aglutinação de trabalho e de dejetos conformam um território de produção e circulação ou, ao menos, de reinserção produtiva de elementos materiais ou não, anteriormente descartados, ou jamais inseridos no processo produtivo de tipo "clássico".

Desse ponto de vista, a descrição da Central de Triagem da Vila Curuçá é significativa. ${ }^{17}$ Em primeiro lugar, entre os 90 e 100 (cifra que varia conforme o período e os ciclos de recepção e venda de dejetos) trabalhadores "cooperados", não se encontram catadores ou ex-catadores, mas ex-trabalhadores assalariados fabris ou do setor de serviços, os quais já chegaram com os procedimentos e a disciplina do trabalho formal incorporados. Um setor que chama atenção no trabalho da Central é a esteira de separação dos materiais recicláveis, onde em dois turnos distintos ocorrem as atividades de separação do que é reciclável e do que deve ser descartado. Ali, há uma intensa rotatividade de trabalhadores, tanto por conta de doença, ${ }^{18}$ como pela prática de "demissão" conforme os rendimentos obtidos e/ou a produtividade do trabalho, ou, ainda, conforme caminha a dinâmica de venda dos materiais processados, dinâmica que, aliás, obedece rigidamente às oscilaçôes do mercado. ${ }^{19} \mathrm{Na}$ esfera da separação e da produção não há predominância de gênero, em contraponto à masculinização dos cargos de gestão e gerência. ${ }^{20}$ Além disso, as funções de mando são centralizadas, independentemente de quem formalmente tenha sido eleito para a coordenação e a presidência da cooperativa. É também bastante frequente a acusação de roubo ou de uso de drogas - "ratos de duas patas", assim são chamados os acusados desses delitos pelos dirigentes.

Além da esteira, que trouxe para a Central o trabalho repetitivo das fábricas, foi possível notar outros elementos advindos das relações fabris autoritárias e centralizadas, como a prática de assédio moral, "demissão" e "readmissão", rotatividade, centralização de mando e de informações etc. Entretanto, é inegável que, com "pulso forte", ${ }^{21}$ a administração conseguiu tornar a cooperativa da Vila Curuçá o exemplo mais bem-sucedido de central de triagem da cidade de São Paulo. Mas para isso, ao que tudo indica, teve de sacrificar seu caráter de cooperativa autogerida, adquirindo para dentro e para fora um caráter empresarial nos moldes antigos, com a implementação de práticas de produção oriundas das formas mais clássicas de exploração do trabalho.

Em contraponto a esta Central de Triagem, visitamos outra cooperativa, menor e constituída de forma diversa. Sua liderança principal afirmou, na última entrevista realizada, em abril de 2009, a absoluta convicção de que a esteira de triagem era "cruel 
demais". Assim, nunca quis de fato utilizar uma esteira mecânica para a separação dos resíduos sólidos em sua "instituição". Essa cooperativa parecia ser gerida de forma mais democrática, acomodando a família da coordenadora e mais doze trabalhadores, na sua maioria mulheres. Ocupava um imóvel de menor proporção, recém-reformado e bastante modificado desde a última visita, no final de 2007. Diante das modificações e da necessidade de rendimentos maiores, a coordenadora nos apresentou novos projetos da cooperativa: uma escola, um centro de capacitação, em imóvel maior, reformado e parcialmente reconstruído, pronto para a aquisição de novos equipamentos. Trata-se do exemplo mais virtuoso de reciclagem da Zona Leste paulista, construído a partir de um novo conjunto de parcerias com a Rede Record de Televisão, com o Instituto Ressoar e as igrejas evangélicas a ele vinculadas.

Mais uma vez vieram à tona as ambiguidades, as liminaridades, ou, mais propriamente, as dobras, mesmo ali onde imaginávamos ter encontrado um projeto mais digno no circuito da reciclagem. Mais uma vez empresas e Estado articulavam-se em empreendimentos e programas que permitiam o uso potencializado de um trabalho precário, total ou parcialmente desprovido de regulação, que se misturava à "viração" e aos "bicos", às vezes elevados à condição de pequenas iniciativas de cunho familiar, na produção de velhas matérias-primas renovadas pelo uso do trabalho, investidas do caráter de "preservação ambiental", "ambientalizadas" e reapropriadas pelo pagamento de preços vis por grandes empresas, que têm o poder de fogo de centralizar mercados setoriais, além de receberem o selo verde de excelência ambiental. Essa suposta ambientalização "pelo bem do planeta" dilui e invisibiliza exatamente o trabalho, revestido de um caráter supostamente cooperativo e "autogerido", com graus de precarização que poderiam estar dispostos em um complexo gradiente que vai da ausência total de direitos até certa formalização do trabalho.

Se comparados às oficinas de costura, o trabalho de reciclagem parece de fato ser menos precário, mas aquilo que tende a desaparecer do processo produtivo mais moderno - as linhas de montagem e as esteiras de produção - é reintroduzido ali, além de vínculos empregatícios frágeis, muito distantes das formas clássicas de assalariamento. Como pensar a natureza dessa nova/velha matéria-prima reintroduzida a preços de mercado no âmbito da produção formal? De imediato, a resposta seria: o que se expulsa desse custo é exatamente o trabalho que nele foi incorporado tanto pela catação como pela triagem e o reprocessamento da matéria-prima. Mas essa certeza só existiria com base em uma pesquisa que pudesse reconstruir custos e lucros de produção e analisar mais detidamente a diferença entre as cadeias de produção de matérias-primas tradicionais e de materiais reciclados. De qualquer forma, é inegável que os trabalhadores e o trabalho propriamente ali realizado parecem desaparecer sob o símbolo ambiental da reciclagem representado pelo Selo Verde estampado nessas instituiçōes e sob "virtuosos" programas de geração de emprego e renda.

Ainda que possam parecer bairros-dormitório, os territórios formados a partir do trabalho de costura ou de reciclagem são palcos de novas formas de inserção produtiva, nódulos importantes nos circuitos de produção e circulação da riqueza, nem sempre visíveis, nem sempre entendidos como tal. É curioso perceber que assim como o trabalho assalariado supostamente perde centralidade e força estruturante, a visibilidade desses novos processos produtivos se recobre de um caráter bastante nebuloso. Para enfrentar isso, é preciso alargar o olhar para além do trabalho fabril e formal, desenhando novos objetos de pesquisa: cadeias produtivas, trabalho precário e informal, trabalho associado, modulações de relações de trabalho clássicas etc. Os processos de produção que têm lugar nesses territórios foram entrevistos, ao menos na investigação ainda em curso, a partir de inserções etnográficas de pesquisa. Foram também compreendidos, ainda que parcialmente, em meio a um conjunto de novas injunçôes. Eles parecem se confundir com programas de geração de renda, com dimensōes associativas, legitimadas por movimentos sociais ou que se assentam nas dimensōes da nova solidariedade, pipocando aqui e ali, onde o encolhimento do emprego assalariado teria deixado um aparente vazio, uma ausência relativa de relações de trabalho. "Sobreviver na adversidade" 22 dos bairros populares e distantes do centro estabelece situações de produção e de moradia em tudo distantes da antiga 
centralidade espacial e temporal da fábrica e do cotidiano operário. Desse ponto de vista, conformam-se circuitos que permeiam as cadeias de produção e de fluxos de circulação da riqueza e que estão longe de serem marginais ou menos importantes para suas práticas e processos de acumulação.

\section{Considerações finais}

Em uma das últimas visitas à cooperativa de costura da Cidade Tiradentes, que denominamos Atrito (Geoges e Rizek, 2008), uma das trabalhadoras da linha de montagem me pediu informaçôes sobre as cooperativas de reciclagem que, segundo pensava, ofereceriam condiçôes muito melhores de trabalho. É como se as pessoas estivessem presas a essas alternativas de trabalho, como se estas fossem tudo o que lhes restasse. Seria possível afirmar que trabalho e território se encontram modulados de outra forma, rompendo as clássicas diferenciações entre espaços de produção de valor e espaços de reprodução da força de trabalho? Nossos resultados apontam para uma resposta positiva. Talvez a questão das relações entre trabalho, produção e cidade não se localize na discussão sobre a centralidade do trabalho ou seu desaparecimento, ou acerca da desterritorialização do capital financeiro e fictício. Talvez os estudos hoje devam focalizar justamente as forças estruturantes que hoje não aparecem claramente quando se analisa as relações entre produção e territórios urbanos; relações aparentemente indeterminadas, constituídas de modo aleatório e obedientes a uma lógica fragmentária. Desta perspectiva, esses espaços certamente não poderiam mais ser reconhecidos como lugares que alojam experiências de classe, como pensou E. P. Thompson, ${ }^{23}$ já que boa parte da experiência vivida nas fábricas, nas moradias, nos espaços de convívio social desapareceu tanto como forma de inserção quanto como expectativa de vida. Mas isso não quer dizer que as articulaçôes entre produção e cidade tenham simplesmente deixado de existir. Com efeito, elas se tornaram menos claras, mas inegavelmente presentes. A incorporação e a exploração da força de trabalho na cadeia produtiva de circulação da riqueza permanecem, só que agora grande parte desse processo se produz e se reproduz nas fronteiras tênues de programas virtuosos de geração de emprego e renda, de gestão do trabalho associado em cooperativas supostamente autogeridas, de um lado, e, de outro, em regimes de uso brutal do trabalho das parcelas mais vulneráveis da população.

Para além dos barracos, do barulho do trem, das formas de crescimento periférico, novas configurações do trabalho, da produção e de suas relações moduladas com o espaço e os tempos da cidade acabam por se revelar, por se impor, como pudemos mostrar a partir desse estudo etnográfico.

\section{Notas}

1 Pesquisa financiada por Bolsa Produtividade CNPq "Da civilidade ao seu avesso: a gestão dos territórios da precariedade".

2 Algumas dessas ideias reaparecem discutidas sob novas chaves em Telles (2006).

3 A ideia é fartamente utilizada em Telles e Cabanes (2005), mas é possível rastrear algumas de suas inspiraçōes em autores como G. Agamben, em Estado de excȩ̧ão por exemplo. A ideia de uma zona nebulosa ou cinzenta de indiferenciação entre regra e exceção pode ser uma das influências dessa noção. Outra dimensão possível, tal como aparece neste texto, é a noção de indeterminação, também utilizada de modo bastante livre no âmbito da discussão que ora se apresenta.

4 Ver, por exemplo, Telles e Hirata (2009). Há uma tradução de São Paulo: la ville d'en bas, recentemente publicada com o título Saidas de emergência: ganharl perder a vida na periferia de São Paulo, organizado por Robert Cabanes, Isabel Georges, Cibele S. Rizek e Vera da Silva Telles (São Paulo, Boitempo, 2011).

5 Pesquisa apoiada por bolsa produtividade CNPq, que dá continuidade a outras investigaçōes já concluídas.

6 Projeto CNPq bolsa Produtividade 2007 - 2010 Cidade, Civilidade e seus avessos - tessituras e gestão dos territórios da precariedade. Esses processos implicaram menos em desindustrialização e muito mais em um uso da força de trabalho que se fragmentou e precarizou por meio de expedientes como downsizing, produção enxuta, novos modos de gestão do trabalho, processos de terceirização e externalização de todos os tipos.

7 Uso a expressão de forma bastante livre. 
8 Na realidade, a categoria "trabalho em domicílio" não se aplica inteiramente a essas situações, em especial as oficinas cujos trabalhadores são bolivianos indocumentados. Se o trabalho em domicílio supunha atividades realizadas nos locais de residência, trata-se aqui do contrário: esses indivíduos habitam os locais onde trabalham.

9 Claro que se pode notar a persistência e o renascimento do trabalho em domicílio como modo de uso do tempo de trabalho e do próprio trabalhador, nesse caso, mulheres. Aqui caberia uma discussão sobre a persistência e a redefinição desse tipo de trabalho. Seria possível objetar que essa situação diz respeito à velha condição operária, configurando cenas muito plausíveis a partir da revolução industrial inglesa. Mas talvez se trate menos de uma persistência do que de uma redefinição em que esse modo de trabalho se combina com outros ao longo da cadeia de produção e de comercialização do setor de confecção.Ver, especialmente, Silva (2008).

10 Refiro-me ao que foi descrito em Geoges e Rizek (2008) ou ainda em Rizek (2010).

11 Utilizo os termos "precariedade" e "informalidade", entre outros, que apontavam para uma característica não regulada e vulnerável das situações de trabalho e portanto para uma ideia negativa da inserção produtiva de camadas populares, apesar de ter em mente que eles não dão conta da gigantesca diversidade de situações que se abrigavam sob tais denominações.

12 Telles desenvolve e utiliza duas noções úteis para a formulação das questôes presentes neste texto. A primeira é a ideia de dobra, que articula legalidades e ilegalidades em um único "arranjo". A segunda é a de "mobilidade lateral", quando a articulação entre o lícito e o ilícito se dá através de uma rede de trabalhadores ou núcleos de produção, não se constituindo em uma prática direta de cada trabalhador. Ver a esse respeito Telles (2009).

13 Uma primeira descrição desses processos, que denomino circuito da reciclagem, foi feita no capítulo "Moradia e Trabalho: entre o trabalho associado e o assalariamento" do livro organizado por Márcia Leite e Isabel Georges (São Paulo, Annablume, no prelo).

14 Ver a esse respeito "La collecte et le traitement de déchets", de Robert Cabanes, Monica Virginia de Souza, em Cabanes e Georges (2009).

15 A expressão é de José Sergio Leite Lopes (2006).

16 Esta constatação não encontra ressonância nos discursos dos dirigentes da Central de Triagem, mas foi observada em entrevistas com diretores e a partir de in- formações obtidas nos núcleos e em outras entidades que compõem o circuito da reciclagem desses bairros.

17 Para viabilizar a cooperativa, vale lembrar que a Central de Triagem contou com o apoio da prefeitura, que paga ou cede caminhōes de coleta (doméstica e de centros comerciais, por exemplo) e entrega do material, bem como o aluguel do grande galpão onde funciona o estabelecimento, no valor de $\mathrm{R} \$ 10.000,00$ mensais. A própria Central e seus cooperados compraram novas máquinas, o que garantiu seu desenvolvimento. Essa iniciativa ocorreu durante a gestão Marta Suplicy na prefeitura de São Paulo. Curiosamente, quando perguntamos ao então presidente da cooperativa o que teria significado a mudança do governo municipal, ele respondeu: "Bom desde que o apoio continue e ele continuou - não significou muita coisa não".

18 Saltam aos olhos a sujeira e as más condições do local de trabalho. O galpão - anteriormente um galpão industrial - é muito quente e comporta tanto o material já separado, como aquele que chega nos caminhōes. Este, por sua vez, ainda está misturado a resíduos de lixo orgânico, facilitando a presença de ratos e insetos. Depois de reciclado e prensado, o material segue para um depósito a céu aberto, onde também se acumulam resíduos de outra natureza.

19 O material é comprado pelas empresas de acordo com o preço de mercado, o que anula quaisquer intenções virtuosas no que diz respeito à geração de emprego e renda e/ou às dimensões ambientais. Assim, as relaçôes com as empresas que centralizam setores produtivos inteiros mudam de registro para afirmar a força das "leis de mercado". Informações obtidas por entrevista realizada com o presidente da cooperativa em abril de 2009.

$20 \mathrm{Na}$ última visita à cooperativa, no final de 2008, havia mudanças: uma mulher tinha sido eleita para a presidência. Entretanto, para nossa surpresa, percebemos que no escritório as tarefas de direção continuavam a ser exercidas pelo presidente anterior, que atuava de modo bastante centralizador, o que foi corroborado em depoimentos de trabalhadores e coordenadores dos núcleos.

21 A expressão é de uma das entrevistadas, cujo tom oscilava entre o respeito pelo caráter bem-sucedido e empresarial da cooperativa e o desprezo pela "mão de ferro" ou "pulso forte" de seu eterno presidente e mandatário, independentemente de quem fosse eleito ou escolhido para o cargo.

22 A expressão é título da tese de doutorado de Daniel Veloso Hirata (2010).

23 Ver, entre outros, Fortes (2006). 


\section{BIBLIOGRAFIA}

BARROS, Joana. (2004), Moradores de rua - trabalho e pobreza: interrogaçôes sobre a exceção e a experiência politica brasileira. São Paulo, dissertação de mestrado, Sociologia, FFLCH-USP.

CABANES, R. \& GEORGES, Isabel. (2009), São Paulo, la ville d'en bas. Paris, L'Harmattan. [Na toa 4 você inseriu uma referência à edição brasileira, mas aparece como organizadores Robert Cabanes, Isabel Georges, Cibele S. Rizek e Vera da Silva Telles (orgs.). E isso mesmo ou aqui falta nomes?]

FORTES, A. (2006), "Miríades por toda a eternidade: a atualidade de E. P. Thompson". Tempo Social, 18 (1): 197-215.

GEOGES, I. \& RIZEK, C. S. (2008), "A periferia dos direitos". Trabalho apresentado no Encontro Anual da Anpocs, Caxambu, MG.

HIRATA, Daniel V. (2010), Sobreviver na adversidade: entre o mercado e a vida. São Paulo, tese de doutorado, Sociologia, FFLCH-USP.

KOWARICK, L. (2009), Viver em risco. São Paulo, Editora 34.

LAGO, Luciana C. (2006), "Baixada: lugar do trabalho ou cidade-dormitório?. Disponível em $<$ www.comcausa.org.br/artigos2009>, consultado em set. 2010.

LEITE LOPES, J. Sergio. (2006), "Sobre processos de 'ambientalização' dos conflitos e sobre dilemas da participação". Horizontes Antropológicos, 12 (25), disponível em <www.Scielo.org.br>.

OLIVEIRA, F. (2003), Crítica à razão dualista/Ornitorrinco. São Paulo, Boitempo.

RIZEK, C. S. (2010), "Verde, amarelo, azul e branco", in F. Oliveira, R. Braga e C. Rizek (orgs.), Hegemonia às avessas, São Paulo, Boitempo.

SILVA, Carlos Freire. (2008), Trabalho informal e redes de subcontratação: dinâmicas urbanas da indústria de confecção em São Paulo. São Paulo, dissertação de mestrado, Sociologia, FFLCH-USP.

TARRIUS, Alain. (2002), La mondialisation par le bas: les nouveaux nomades de l'économie souterraine. Paris, Balland.

TELLES, V. S. (2006), "Mutações do trabalho e experiência urbana". Tempo Social, 18 (1): 173-195.
TELLES, V. S. \& HIRATA, Daniel Veloso. (2009), "Ilegalismos e jogos de poder em São Paulo". Tempo Social, 22 (2): 39-59.

TELLES, V. S. \& CABANES, R. (2005), Nas tramas da cidade. São Paulo, Humanitas. 


\section{TRABALHO, MORADIA \\ E CIDADE: ZONAS DE \\ INDIFERENCIAÇÃO?}

\section{Cibele Saliba Rizek}

Palavras-chave: Trabalho; Circuitos produtivos; Moradia; Pobreza.

A partir de observações etnográficas, este artigo busca detectar algumas das forças estruturantes presentes nas relações entre transformações provenientes dos processos de mundialização e suas modulações locais no âmbito brasileiro. A mundialização, no contexto nacional e, especificamente na cidade de São Paulo, produziu transformações silenciosas nos espaços urbanos por meio da articulação nem sempre visível entre o chamado "mundo do trabalho" e o "mundo da moradia".

\section{HOUSING, WORK, AND URBAN LIFE: ZONES OF UNDIFFERENTION?}

\section{Cibele Saliba Rizek}

Keywords: Work; Productive circuits; Housing; Poverty.

Rooted in ethnographic findings, this article wants to show that structuring forces are still present among the changes observed in the poor territories of São Paulo, even when invisible, modulated by the mix between the processes identified as global changes and its local developments, like the impact of the so-called "Chinese cost" in work relations. In a European context, the global processes may have the meaning of porosity and traffic among frontiers, international migrations, trade means crossing formal and informal poles of circulation and consumption. In the east of São Paulo it is possible to observe other modulations of these processes. Part of them have taken place with a silent and invisible transformation of urban territories, mixing the so-called "world of housing" and the "world of work."

\section{TRAVAIL, LOGEMENT ET VILLE: ZONES D'INDIFFÉRENCIATION?}

\section{Cibele Saliba Rizek}

Mots-clés: Travail; Circuits productifs; Logement; Pauvreté.

À partir d'observations ethnographiques, cet article cherche à identifier quelques forces structurantes présentes dans les rapports entre transformations issues des processus de mondialisation et ses modulations locales dans le cadre brésilien. La mondialisation, dans le contexte national et, particulièrement, dans la ville de São Paulo, a produit des transformations silencieuses dans les espaces urbains par une articulation, pas toujours visible, entre le "monde du travail" et le "monde du logement". 